\title{
Basic Abnormalities in Visual Processing Affect Face Processing at an Early Age in Autism Spectrum Disorder
}

Citation for published version (APA):

Vlamings, P. H. J. M., Jonkman, L. M., van Daalen, E., van der Gaag, R., \& Kemner, C. (2010). Basic Abnormalities in Visual Processing Affect Face Processing at an Early Age in Autism Spectrum Disorder. Biological Psychiatry, 68(12), 1107-1113. https://doi.org/10.1016/j.biopsych.2010.06.024

Document status and date:

Published: 15/12/2010

DOI:

10.1016/j.biopsych.2010.06.024

Document Version:

Publisher's PDF, also known as Version of record

\section{Document license:}

Taverne

Please check the document version of this publication:

- A submitted manuscript is the version of the article upon submission and before peer-review. There can be important differences between the submitted version and the official published version of record.

People interested in the research are advised to contact the author for the final version of the publication, or visit the DOI to the publisher's website.

- The final author version and the galley proof are versions of the publication after peer review.

- The final published version features the final layout of the paper including the volume, issue and page numbers.

Link to publication

\footnotetext{
General rights rights.

- You may freely distribute the URL identifying the publication in the public portal. please follow below link for the End User Agreement:

www.umlib.nl/taverne-license

Take down policy

If you believe that this document breaches copyright please contact us at:

repository@maastrichtuniversity.nl

providing details and we will investigate your claim.
}

Copyright and moral rights for the publications made accessible in the public portal are retained by the authors and/or other copyright owners and it is a condition of accessing publications that users recognise and abide by the legal requirements associated with these

- Users may download and print one copy of any publication from the public portal for the purpose of private study or research.

- You may not further distribute the material or use it for any profit-making activity or commercial gain

If the publication is distributed under the terms of Article 25fa of the Dutch Copyright Act, indicated by the "Taverne" license above, 


\title{
Basic Abnormalities in Visual Processing Affect Face Processing at an Early Age in Autism Spectrum Disorder
}

\author{
Petra Hendrika Johanna Maria Vlamings, Lisa Marthe Jonkman, Emma van Daalen, \\ Rutger Jan van der Gaag, and Chantal Kemner
}

\begin{abstract}
Background: A detailed visual processing style has been noted in autism spectrum disorder (ASD); this contributes to problems in face processing and has been directly related to abnormal processing of spatial frequencies (SFs). Little is known about the early development of face processing in ASD and the relation with abnormal SF processing. We investigated whether young ASD children show abnormalities in low spatial frequency (LSF, global) and high spatial frequency (HSF, detailed) processing and explored whether these are crucially involved in the early development of face processing.
\end{abstract}

Methods: Three- to 4-year-old children with ASD $(n=22)$ were compared with developmentally delayed children without ASD ( $n=17)$. Spatial frequency processing was studied by recording visual evoked potentials from visual brain areas while children passively viewed gratings (HSF/LSF). In addition, children watched face stimuli with different expressions, filtered to include only HSF or LSF.

Results: Enhanced activity in visual brain areas was found in response to HSF versus LSF information in children with ASD, in contrast to control subjects. Furthermore, facial-expression processing was also primarily driven by detail in ASD.

Conclusions: Enhanced visual processing of detailed (HSF) information is present early in ASD and occurs for neutral (gratings), as well as for socially relevant stimuli (facial expressions). These data indicate that there is a general abnormality in visual SF processing in early ASD and are in agreement with suggestions that a fast LSF subcortical face processing route might be affected in ASD. This could suggest that abnormal visual processing is causative in the development of social problems in ASD.

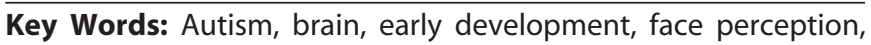
spatial frequency, visual

A utism spectrum disorder (ASD) is a complex neurodevelopmental disorder characterized by impairments in communication and social interaction and stereotyped patterns of behavior and interests (1). Although impairments in the social domain are the best-known characteristics of ASD, a large and still growing number of studies consistently report abnormalities in visual perception in ASD, indicating that perception is more locally or detail oriented (2-5). Interestingly, there are recent indications that this abnormal perception might be primary or at least contributory to abnormalities in social processing in this group and especially in atypical processing of the faces of others (5-9).

More specifically, it has been suggested that the primacy for detail in ASD is related to impairments in one of the most fundamental aspects of human vision $(10,11)$, namely the processing of spatial frequencies $(6-9,12)$. Although there is a certain amount of overlap between high spatial frequency (HSF) and low spatial frequency (LSF) processing (10), in general, HSF are important for detailed perception and represent sharp edges and fine perceptual detail (Figures S1 and S2 in Supplement 1). Low spatial frequencies,

From the Developmental Cognitive Neuroscience (PHJMV, LMJ), Department of Cognitive Neuroscience, Faculty of Psychology, Universiteit Maastricht, Maastricht; Department of Child and Adolescent Psychiatry (EvD, CK), University Medical Center, Utrecht; and Karakter (RJvdG), University Centre for Child and Adolescent Psychiatry, Nijmegen, The Netherlands.

Address correspondence to Petra Vlamings, Ph.D., Maastricht University, Faculty of Psychology, Department of Cognitive Neuroscience, PO Box 616,6200 Maastricht, MD, The Netherlands; E-mail: Vlamings@ psychology.unimaas.nl.

Received Jan 26, 2010; revised May 21, 2010; accepted Jun 15, 2010. on the other hand, provide information about the general shape, proportions, and large contours of objects (13-15). Importantly, several studies have indicated that LSF information is crucial for rapid and efficient processing of facial information and specifically activates fast subcortical threat/saliency detection systems in the brain (16-19). In this way, specialized processing of LSF information is believed to mediate fast and unconscious adjustments of behavior.

Several studies suggest that the focus on local information in ASD is related to a relative overprocessing of HSF $(6-9,12)$. Some behavioral studies in children and adults, for example, demonstrate that, in contrast to control subjects, face perception is guided by HSF in ASD in tasks measuring identity and emotion recognition $(6,7,9)$. Atypical processing of HSF in ASD has also been found in a visual evoked potential (VEP) (12) as well as an electroencephalographic (EEG) study (20), both using simple grating stimuli that are typically used to investigate the basics of spatial frequency processing. It therefore seems that, for social as well as nonsocial information, there is a bias toward the use of local information and HSF in adults and children with ASD.

There are a few studies reporting impairments and atypical neural processing of facial emotions in infants and toddlers with ASD (21-23). For example, although typically developing children are able to differentiate facial expressions at 6 months and recognize the primary facial emotions during toddlerhood (24), toddlers with ASD show difficulties in this respect. However, it is unknown whether deviant visual perception or spatial frequency (SF) processing is present at an early age in ASD and whether it influences face processing at this age. Because the young brain is the most capable of learning, better understanding of the functional relationship between visual perception and face processing in young ASD patients is needed to tailor early treatment. In the present study, we investigated the interplay between basic abnormalities in spatial frequency processing and face perception in a group of 3- to 
4-year old children with ASD and age- and IQ-matched control subjects. We measured VEPs in response to nonsocial stimuli (gratings) as well as to social stimuli (facial expressions) and measured the latencies and amplitudes of VEP peaks specifically sensitive to the spatial frequency content of both stimulus types. More specifically, we investigated two event-related potential (ERP) peaks, the $\mathrm{P} 1$ and the N170. The P1 and N170 can be measured in both adults and children, although they occur at longer latencies in children (25-27). The P1 is an early peak (latency at about $100 \mathrm{msec}$ ) that is mostly associated with sensory processing in early striate and extrastriate areas and can be seen to both gratings (12) and face stimuli (26). The N170 is a face-specific peak; it reflects processing later in time and results from a network of regions including the fusiform gyrus (28). Both peaks are sensitive to facial expressions and to the spatial frequency content of the presented stimuli (see [19] for review). Because the evidence, so far, mainly supports enhanced detail or HSF processing in ASD, we predict a bias toward HSF processing in our clinical group, reflected in the amplitude of the P1 to gratings. Second, based on above discussed behavioral work in ASD (6-9) and previous work on the role of SF in the rapid processing of emotion in control subjects $(17,19,29)$, we predict that increased HSF processing in children with ASD will also affect their processing of facial expressions and that this will be reflected in the P1 and N170 to faces.

\section{Methods and Materials}

\section{Participants}

In total, 29 children diagnosed with ASD and 18 control children with developmental delay but without ASD participated. Seven ASD children (of 29) were excluded because they were not compliant with the EEG procedure and one control child was excluded because of medication use. The final groups comprised 22 children with ASD and 17 control subjects. All children had normal or corrected to normal vision. Information on several diagnostic instru- ments (30-32) is presented in Table 1. Details on participant recruitment, exclusion criteria controls, and diagnostic methods can be found in Supplement 1. Groups did not differ in sex, chronological age, nonverbal mental age, or verbal age (Table 1).

The experimental protocol was approved by the Medical Ethical Committee of the Radboud Hospital in Nijmegen and all parents gave written informed consent before participation.

\section{Stimuli and Task Procedure}

The grating and facial emotion tasks were administered in separate sessions that took place on different days (session 1, gratings task; session 2, facial emotion task). Four ASD children participated in session 1 only.

Grating Task. Horizontal (square-wave) black-and-white gratings with either an HSF (6 cycles per degree $[\mathrm{c} / \mathrm{d}])$ or an LSF $(.75 \mathrm{c} / \mathrm{d})$ (Figure S1 in Supplement 1) were randomly presented on a computer with a duration of $500 \mathrm{msec}$. The task consisted of three blocks containing 60 trials each ( $30 \mathrm{HSF}$ and $30 \mathrm{LSF}$ ). To motivate the children to attend the stimuli, each block also contained 10 different moving and colored animations (10 per block; duration, $2000 \mathrm{msec}$ ), clearly differing from the grating stimuli. Participants were instructed to attend to all pictures and to respond to all animations with a button press. No responses were required for the gratings. After a hit (button press within $3000 \mathrm{msec}$ after onset) a happy sound ("yoohoohoohoo") was presented; after a miss, a negative sound ("boing") was played. At the beginning of the session, there was one practice block containing 48 trials and five animations. The active task (pushing the response button on animation onset) was only included to increase children's attention to the screen. There were no group differences in the number of children that were able to actively perform the task (control subjects, 70\%; ASD, 64\%; Fisher's exact test, $p=.74$ ) and accuracy rates of these children did not differ between groups [control subjects, 86\%; ASD, $93 \% ; F(1,23)=1.51, p=.23]$.

Facial Emotion Task. Filtered face stimuli were presented that

Table 1. Descriptive Data for ASD Children and Control Subjects

\begin{tabular}{|c|c|c|c|}
\hline Variable & $\begin{array}{l}\text { Autism Spectrum Disorder } \\
\qquad(n=22)\end{array}$ & $\begin{array}{l}\text { Control Subjects } \\
\quad(n=17)\end{array}$ & $t$ and $p$ Values \\
\hline Male (Female) & $19(3)$ & $13(4)$ & Fisher's exact test, $p=.67$ \\
\hline \multicolumn{4}{|l|}{ CA (Months) } \\
\hline Range & $35-60$ & $36-67$ & \\
\hline Mean \pm SEM & $48.4 \pm 1.3$ & $51.6 \pm 2.6$ & $t(37)=1.12, p=.28$ \\
\hline \multicolumn{4}{|l|}{ Nonverbal MA } \\
\hline Range & $18-61$ & $19-60$ & \\
\hline Mean \pm SEM & $37.4 \pm 2.7$ & $35.9 \pm 2.5$ & $t(37)=-.40, p=.69$ \\
\hline \multicolumn{4}{|l|}{ Verbal MA } \\
\hline Range & $8-63$ & $11-70$ & \\
\hline Mean \pm SEM & $35.5 \pm 3.6$ & $36.5 \pm 3.8$ & $t(37)=-.20, p=.84$ \\
\hline SCQ Score (cutoff $=15)$ & NA & $8 \pm 1.4$ & \\
\hline \multicolumn{4}{|l|}{ ADI-R Score $\pm S D$} \\
\hline Social behavior (cutoff $=10$ ) & $14.3 \pm 6.4$ & NA & \\
\hline Communication (cutoff $=8$ ) & $10.1 \pm 4.4$ & NA & \\
\hline Repetitive behavior (cutoff $=3$ ) & $4.1 \pm 2.8$ & NA & \\
\hline \multicolumn{4}{|l|}{ ADOS Scores $\pm S D$} \\
\hline Communication (cutoff $=2$ ) & $3.7 \pm 2.0$ & NA & \\
\hline Social behavior (cutoff $=4$ ) & $8.3 \pm 2.8$ & NA & \\
\hline \multicolumn{4}{|l|}{ Clinical Diagnosis } \\
\hline PDD-NOS & 7 & & \\
\hline Autism & 15 & & \\
\hline
\end{tabular}

ADI-R, Autism Diagnostic Interview-Revised (30); ADOS, Autism Diagnostic Observation Schedule (31); ASD, autism spectrum disorder; CA, chronological age; MA, mental age; NA, not administered; PDD-NOS, Pervasive Developmental Disorder-Not Otherwise Specified; SCQ, Social Communication Questionnaire (32). 


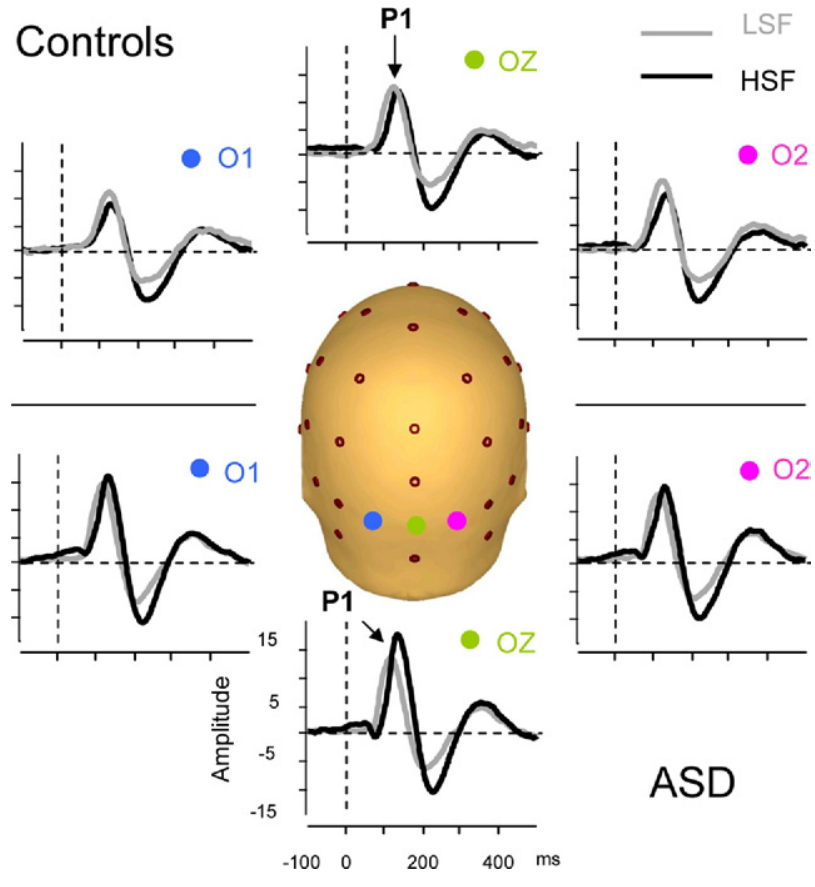

Figure 1. Grand average visual evoked potentials at $\mathrm{OZ}, \mathrm{O} 1$, and $\mathrm{O} 2$ in response to high spatial frequency (HSF) and low spatial frequency (LSF) gratings (in black and red, respectively) for both groups. Upper, control group; lower, autism spectrum disorder group. ASD, autism spectrum disorder; P1, event-related potential peak.

consisted of 16 grayscale images ( 8 male images, 8 female images), one half depicting a neutral expression, the other half depicting a fearful expression. Choice of these expressions was based on previous studies $(16,17,19,33)$ that all used neutral and fearful expressions to investigate the role of SF in emotion processing by measuring neural activity. The photographs were selected from the NimStim Set (34) (The Research Network on Early Experience and Brain Development, http://www.macbrain.org/faces/index.htm). The HSF images were created by filtering the original photographs using a high-pass cutoff of $\geq 6 \mathrm{c} / \mathrm{d}$ of visual angle for the HSF stimuli and a low-lass filter of $\leq 2 \mathrm{c} / \mathrm{d}$ of visual angle for the LSF stimuli (Figure S2 in Supplement 1). Filtering was performed in Matlab (The MathWorks, Natick, Massachusetts) using a set of Gaussian filters.

The facial emotion task consisted of four blocks each of 73 trials. Within each block, 64 faces and 9 moving animation figures, the latter requiring a button press, were presented on a gray background in randomized order. All faces were presented for $500 \mathrm{msec}$ with an interstimulus interval of $1600 \mathrm{msec}$ to $1800 \mathrm{msec}$. There were no group differences in the number of children that were able to actively perform the task (control subjects, 75\%; ASD, 87\%; Fisher's exact test, $p=.65$ ) and accuracy rates of these children did not differ between groups [control subjects, $87 \%$; ASD, $85 \% ; F(1,23)=$ $.06, p=.81]$.

To monitor the child's looking behavior, all sessions were videotaped. By coding the videos after testing, trials at which children looked away from the screen (at stimulus onset) could be traced. Children were rewarded for participation with a small present. More details on the task procedure and the stimuli can be found in Supplement 1.

\section{ERP Recordings}

Event-related potentials were recorded via an EasyCap (Compumedics, Victoria, Australia) containing 39 electrodes (see Supple- ment 1 for EEG-measurement specifics). Trials during which the child did not look at the screen at stimulus onset were discarded. In the gratings task, all children passed the criteria of 25 trials per condition after rejection of artifacts and trials of inattention. For the grating task, the final groups comprised 22 children with ASD and 17 control subjects. There were no significant group differences in the number of trials included in the analysis $[t(37)=1.61, p<.12]$. In the face task, three ASD children and one control subject did not pass the criterion of 25 trials per condition (HSF fear, HSF neutral, etc.) and were excluded. Interestingly, we observed a significant negative correlation between number of trials on which children with ASD looked at the screen in the face task and level of social behavior $[r(17)=-.62, p<.01]$ and communication $[r(17)=-.61$, $p<.05$ ] as measured by the Autism Diagnostic Observation Schedule. There were no correlations between looking behavior and Autism Diagnostic Observation Schedule measures in the grating task. For the face task, the final groups comprised 15 children with ASD and 16 control subjects. After exclusion of the children who did not meet the criteria of 25 trials per condition, groups did not differ in number of trials included in the analysis of the facial emotion task $[t(29)=.34, p=.74]$. Neither did the groups differ in sex or chronological, mental, or verbal age. Separate ERP averages were computed for all subjects for the stimulus conditions of interest (gratings task, HSF/LSF; facial emotion task, HSF neutral, HSF fear, LSF neutral, LSF fear). Finally, the data were re-referenced to an average reference.

\section{Data Analysis}

Grating Task. With respect to the grating task, we tested whether there were between-group differences in SF processing as reflected by the mean area amplitude and peak latency of the $P 1$ to grating stimuli at occipital electrodes $(\mathrm{Oz}, \mathrm{O} 1$, and $\mathrm{O} 2$; Figures 1 and 2 ), because these are leads where maxima were present and effects are typically seen in healthy adults (12). The P1 mean area amplitudes and latency were determined using predefined time windows (LSF: 90-130; HSF: 110-150) that were based on visual inspection of the grand averages. Peaks were confirmed by visual inspection and
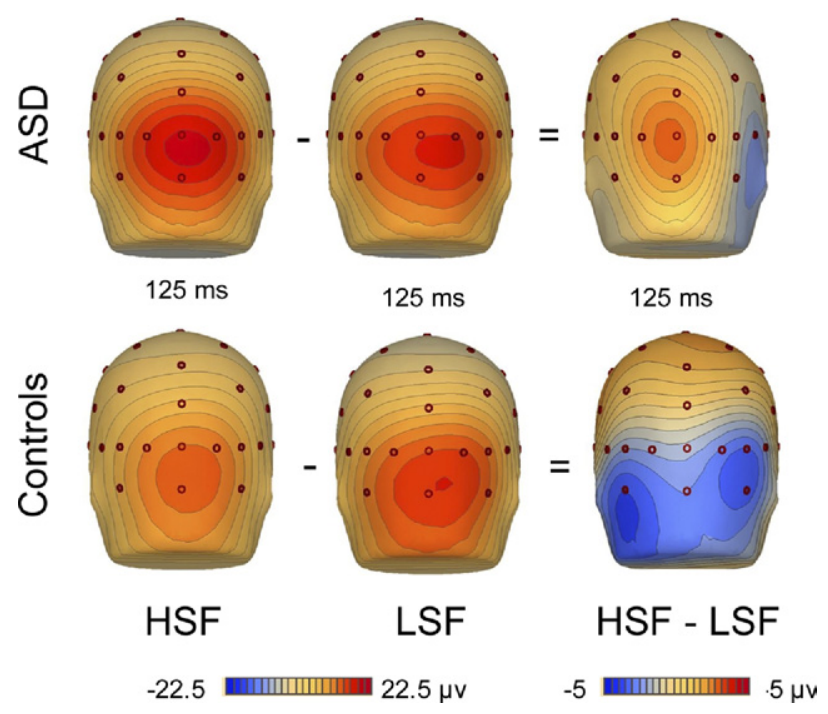

Figure 2. Voltage scalp distribution maps at $125 \mathrm{msec}(\mathrm{P} 1)$ for high spatial frequency (HSF) and low spatial frequency (LSF) gratings for control children (lower) and for children with autism spectrum disorder (upper). In addition, the voltage scalp distribution of the difference in event-related potential amplitude between HSF and LSF is shown (HSF-LSF) at $125 \mathrm{msec}$. ASD, autism spectrum disorder. 
Gratings

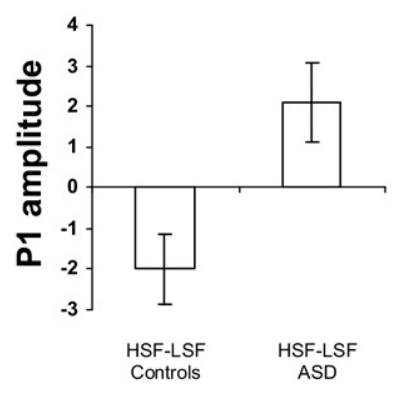

Faces

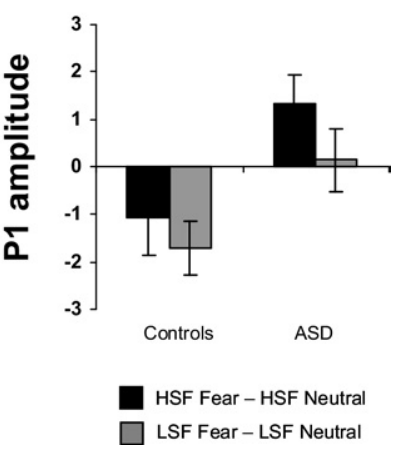

Figure 3. Bar graphs of difference scores $(+\mathrm{SE})$ for the mean amplitudes of the $\mathrm{P} 1$ in all stimulus conditions are shown separately for each age group. ASD, autism spectrum disorder; HSF, high spatial frequency; LSF, low spatial frequency; P1, event-related potential peak.

clearly visible in all participants. Amplitudes and latencies were averaged over the three electrodes and subjected to a 2 (SF, HSF, LSF) $\times 2$ (groups: control subjects, ASD) analysis of variance. Statistically significant interactions were further explored by planned comparisons. When testing of such interactions failed to reveal statistically significant results, these are not discussed.

The Facial Emotion Task. To examine between-group differences in facial expression processing in each of the two SF categories, P1 and N170 amplitudes were analyzed (see above). The latter was not addressed for latency because no effects of SF on emotion were seen in the averages for latency (Figure 4) and no effects were reported in earlier studies $(17,19)$. The mean area amplitude of the $\mathrm{P} 1$ was measured at OZ, O1, O2, PO7, and PO8 and N170 amplitude was measured at P7, P8, PO7, and PO8, where amplitude was maximal. Predefined time windows were LSF 95 to 165 and HSF 135 to 205 for P1 and LSF 170 to 270 and HSF 200 to 300 for N170. Clear P1 and N170 components were observed in all participants.

Hypothesis-driven analyses were carried out to provide sensitive tests of the a priori predictions for each SF type (35). Peak amplitude was pooled across the involved electrodes and subjected to a 2 (emotion: neutral/fear) $\times 2$ (groups: control subjects, ASD) analysis of variance, separately for HSF and LSF to test the prediction that emotion processing would be driven by HSF in the ASD group and mediated by LSF in control subjects. Significant interactions were further tested using planned comparisons.

\section{Results}

\section{Grating Task: P1 Amplitude and Latency}

Grand averages of the P1 are shown in Figure 1. There was a significant interaction between $S F$ and group $[F(1,37)=9.00, p<$ $.01, \eta_{p}^{2}=.20$ ] for P1. Further analysis of this interaction indicated that in the ASD group HSF gratings elicited significantly higher P1 amplitudes compared with those in response to LSF gratings $[t(21)=$ $\left.-2.12, p<.05, \eta_{p}^{2}=.18\right]$, whereas in control subjects the pattern was reversed-LSF gratings evoked higher P1 amplitudes than HSF gratings $\left[t(16)=2.30, p<.05, \eta_{p}^{2}=.25\right]$ (Figures 2 and 3 ). Comparison of P1-HSF amplitudes between groups indicated that this was mainly due to higher P1-HSF amplitude in the ASD group $[t(37)=$ $-1.97, p<.05$, one-tailed; $\left.\eta_{p}^{2}=.10\right]$. With respect to the $\mathrm{P} 1$ latency, there was a main effect of SF, indicating faster latencies for LSF compared with HSF irrespective of group $[F(1,37)=27.77, p<.001$; $\left.\eta_{p}^{2}=.10\right]$.

\section{Facial Emotion Task: P1 and N170 Amplitudes}

Grand averages of the P1 and N170 are shown in Figure 4. As expected, a significant interaction between group and emotion was present for both $\operatorname{HSF}\left[F(1,29)=5.83, p<.05 ; \eta^{2}=.17\right]$ and LSF $\left[F(1,29)=4.53, p<.05 ; \eta_{p}^{2}=.13\right]$ for $\mathrm{P} 1$. Importantly, and consistent with the predictions, the emotion effect at the P1 was only significant for HSF in the ASD group $\left[t(14)=-2.23, p<.05 ; \eta_{p}^{2}=\right.$ $.26]$ and for LSF in the control subjects $\left[t(15)=3.03, p<.01 ; \eta_{p}^{2}=\right.$ .40]. More specifically, in children with ASD, fearful faces elicited higher P1 amplitudes than neutral faces only in the HSF condition, whereas control children showed higher P1 amplitudes to neutral than fearful faces, only in the LSF condition (Figures 2 and 4). Children with ASD showed no emotion effect in the LSF condition [ $t(14)=$ $.84, p<.84]$ and control subjects did not show an effect in the HSF condition $[t(15)=1.37, p<.20]$. No significant effects were found for N170 amplitude, also when correcting for differences at the P1. With respect to the $\mathrm{P} 1$ and $\mathrm{N} 170$ latency, there was a main effect of $\mathrm{SF}$, indicating faster latencies for LSF compared with HSF irrespective of group $\left[\mathrm{P} 1: F(1,29)=493.31, p<.001 ; \eta_{\mathrm{p}}^{2}=.94 ; \mathrm{N} 170: F(1,29)=\right.$ $\left.128.37, p<.001 ; \eta_{p}^{2}=.82\right]$.

\section{Patterns of Brain Activity in Both Tasks}

To investigate whether an HSF bias for processing of nonsocial as well as social stimuli was more prevalent among children with ASD a post hoc frequency analysis was performed. We counted the number of children that had 1) larger $\mathrm{P} 1$ amplitudes to HSF relative to LSF gratings and 2) a larger P1 amplitude difference between neutral and fearful faces (irrespective of sign) in the HSF relative to the LSF condition. A significantly larger group of children with ASD (ASD, 40\%; control subjects, $6 \%$ ) showed a co-occurence of an HSF bias for the processing of gratings as well as the emotional content of faces (Fisher's exact test, $p<.05$ ).

\section{Discussion}

Abnormalities in visual perception in ASD, in particular a more detailed-oriented perception, are seen as primary or at least con-

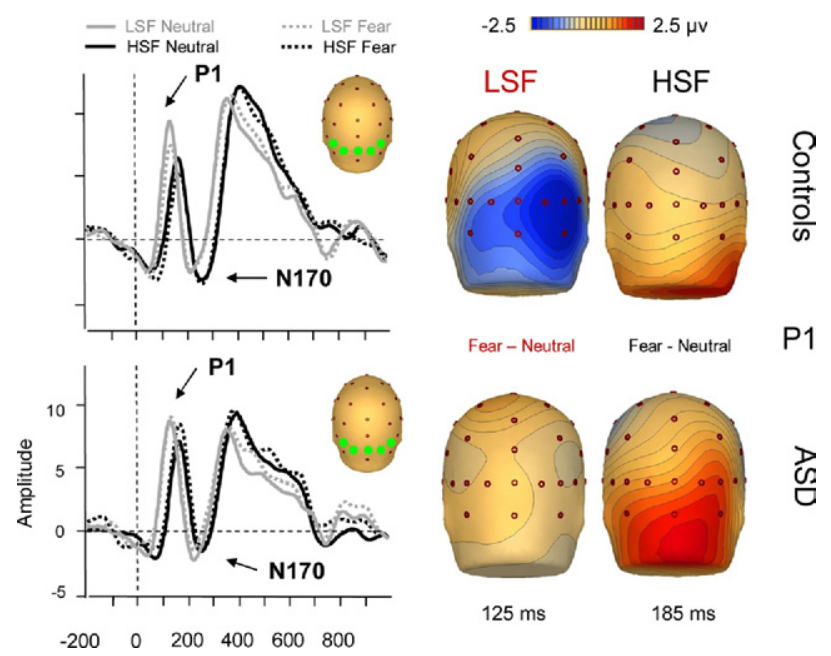

Figure 4. Grand-average event-related potentials at pooled electrodes $\mathrm{PO} 7$, $\mathrm{PO} 8, \mathrm{OZ}, \mathrm{O} 1$, and $\mathrm{O} 2$ in response to high spatial frequency (HSF; black) and low spatial frequency (LSF; red) fearful (dashed) and neutral (continuous) faces for both groups. Upper, control group; lower, autism spectrum disorder group. In addition, the voltage scalp distribution of the difference in event-related potential amplitude between fearful and neutral expressions (fear-neutral) at the P1 peak (LSF, $125 \mathrm{msec}$; HSF, $185 \mathrm{msec}$ ) is shown for HSFs and LSFs. ASD, autism spectrum disorder; N170, face-specific peak; P1, event-related potential peak. 
tributory to problems in face processing in ASD (2-6). However, there is little knowledge on the role of perceptual abnormalities and its influence on face perception in young children with ASD.

In the present study, we investigated a fundamental aspect of vision that is related to detail perception, namely spatial frequency processing, in young children with ASD using visual evoked potentials to HSF (detailed) and LSF (global) patterns. Results clearly show enhanced neural activity to HSF than LSF gratings in the early stages of visual processing (P1) in 3- and 4-year-olds with ASD compared with control subjects matched for mental age. This processing bias for HSF information in the primary visual cortex could provide a potential biological explanation for the detail-oriented perception reported in behavioral studies in children and adults (2-4) and recently also in young children with ASD (36).

Interestingly, the increased P1 brain activity to HSF compared with LSF gratings in children with ASD resembles the activity patterns seen in healthy adults (37-41). By contrast, and consistent with the literature, our young control children showed relatively small amplitudes to HSF stimuli (42). The latter effect has been suggested to reflect relatively late development of the (subcortical) parvocellular system that carries high contrast and HSF information (42). In light of this literature, the present results might suggest that the parvocellular system is more mature in 3- to 4-year-old children with ASD. However, alternative explanations should also be considered because VEPs are recorded from cortical neurons and these are not linked in a one-to-one manner with the parvocellular and magnocellular systems (43). Possibly, children with ASD have other abnormalities in visual cortical areas (e.g., neuronal tuning to a higher range of SFs) or show abnormalities in the macular part of the retina that is also important for the processing of HSF information.

Notably, all children tested in the present study met strict criteria for an ASD disorder based on both a parent interview and on a child observation instrument and were well matched with control subjects on chronological and verbal age as well as levels of attention (by scoring and correcting for looking behavior). In addition, it is very unlikely that group differences found with respect to HSF in the grating task are caused by differences in acuity or contrast sensitivity between the groups. The SF range $(6 \mathrm{c} / \mathrm{d})$ of the gratings was well within the range of grating acuity at 3 to 4 years (44) and gratings were presented at maximal (100\%) contrast. Also, all individuals had normal or corrected to normal vision.

Importantly, the present study indicates that the HSF bias in spatial frequency processing is not restricted to nonsocial (grating) stimuli but also plays an important role in the processing of emotional facial expressions in the same age group. We provide first evidence that the fast extraction of emotion information from a face in the visual cortex (reflected in the P1 amplitude) is driven by HSF information in a group of 3- and 4-year-olds with ASD, whereas in the control group such emotion processing is driven by LSF (see also $[17,19])$. In agreement with a previous study $(27)$, which indicated that emotion effects at the $\mathrm{N} 170$ did not mature until adolescence, we found that emotion did not yet influence the N170 in the present age group.

The finding that children with ASD did not show emotion effects in the LSF condition, as is usually found in healthy participants $(16,17,19,32)$, might be seen as support for theories stating that ASD patients have a disruption in a fast subcortical processing route that is known to play an important role in the processing of emotional expressions $(6,18,45)$. This route involves the amygdala and is preferentially tuned to LSF because of its excessive magnocellular input via the superior collicus and pulvinar $(16,17,32)$. Whereas the behavioral literature on face processing abnormalities in ASD is still highly contentious (46), in general it indicates that individuals with
ASD are deficient in processing emotional expressions (see for review [47]). By measuring time-sensitive VEPs, our results show that there is indeed early visual processing of emotional content in 3- to 4-year-old children with ASD but also that this processing is atypical, as it is based on HSF, i.e., detailed, information. These results support earlier behavioral evidence showing that emotion and identity recognition are primarily driven by HSF information in older children and adults with ASD $(6,7,9)$. The present data demonstrate that this HSF bias in ASD is already present in early childhood and might be due to basic visual processing abnormalities in the brain.

Early tuning toward HSF information in faces might directly affect the development of the network of brain areas that are involved in face processing. The subcortical LSF face processing route that was introduced in the previous paragraph has been suggested to lay the foundation for what later becomes the adult face processing network (18). An early imbalance in the processing of spatial frequencies, as established in the present 3- to 4-year-old ASD children, could affect the normal development of such a network and might have important consequences for the development of emotion processing or social interaction. The subcortical face processing route has also been suggested to be responsible for early orienting to faces (18). There is evidence that abnormal orienting to faces in young children with autism relates to the severity of social symptoms $(48,49,50)$. Such a relation was indirectly confirmed in the present study by the finding that the number of trials at which children looked at the screen significantly correlated with social and communication symptom severity.

Consistent with all previous studies $(16,17,19,32)$ that investigated the influence of SF on emotion processing by measuring neural activity, we measured responses to neutral and fearful expressions. Unexpectedly, the control children in the present study showed enhanced VEP amplitudes in response to neutral, instead of fearful, faces, whereas in healthy adults the opposite pattern is found. Thomas et al. (50) reported enhanced amygdala activation to fearful faces in adults but to neutral faces in children and attributed this effect to enhanced ambiguity of neutral faces for children.

It must be emphasized that not all children with ASD showed atypical SF processing in both the grating and emotion tasks, although the percentage of children who did was considerably larger in the ASD than control group. Recent papers have highlighted the symptom variability in the ASD population and emphasized the search for relevant subgroups $(51,52)$. It is important to investigate in future studies whether subgroups can be discriminated based on different biases in SF processing. Nevertheless, it can be concluded that an HSF processing bias for nonsocial (gratings) as well as social (face) stimuli in ASD is robust across age because the present study, as well as other studies in later childhood and adulthood $(6-9,12)$, all report this bias.

The present findings agree with previous studies that have noted a detailed processing style in ASD patients. These studies have, for example, indicated superior performance on tasks that require local or detailed-focused processing (e.g., embedded figures task, block-design task) (2-4). Whether global processing is also affected in ASD is a subject of ongoing controversy. However, there is increasing evidence that people with ASD are capable of global processing $(4,53-57)$ and that deficits in tasks that probe global processing are related to the detailed processing bias seen in ASD (4), as well as task instructions and complexity of the stimulus $(53,58,59)$. In agreement with this, we found an HSF processing bias for detailed (HSF) relative to global information (LSF) for both social and nonsocial stimuli in the present study. Furthermore, our find- 
ings are consistent with theories that situate the mechanism of a local bias at the level of perception $(4,60)$.

In summary, the present study provides the first evidence for a basic abnormality in visual processing that is directly related to abnormal face processing in young children with ASD. More specifically, children with ASD showed enhanced brain responses to HSF information in the visual cortex for neutral stimuli (gratings), as well as for socially relevant information (larger emotion effects in HSF). The diminished emotion effects in the LSF condition might suggest that the rapid subcortical LSF route for facial expression processing is already affected at an early age in ASD.

All authors had full access to all of the data in the study and take responsibility for the integrity of the data and the accuracy of the data analysis.

We gratefully thank all children and their parents for participating in this study. Furthermore, we are grateful to Anneke de Koning, Anouk Krijgsman, Cecile Pinckaers, and Deliane van Vliet for helping with the data collection; Claudine Dietz, Meinke Jansen, Agnes Jonkman, Judith Kramer, Stephanie Spierts, Marloes Rikken, Emmie van Schaffelaar, and Janne Visser for their help with participant recruitment; and Sanne Haspels, Sabine Koenraads, Iris Ooserling, and Manja van der Smagt for their help in collecting diagnostic data.

The authors report no biomedical financial interests or potential conflicts of interest.

\section{Supplementary material cited in this article is available online.}

1. American Psychiatric Association (1994): Diagnostic and Statistical Manual of Mental Disorders, 4th ed. Washington, DC: American Psychiatric Publishing.

2. Dakin S, Frith U (2005): Vagaries of visual perception in autism. Neuron 48:497-507.

3. Happé F, Frith U (2006): The weak coherence account: Detail-focused cognitive style in autism spectrum disorders. J Autism Dev Disord 36:5-25.

4. Mottron L, Dawson M, Soulières I, Hubert B, Burack J (2006): Enhanced perceptual functioning in autism: An update, and eight principles of autistic perception. J Autism Dev Disord 36:27-43.

5. Behrmann M, Thomas C, Humphreys K (2006): Seeing it differently: Visual processing in autism. Trends Cogn Sci 10:258-264.

6. Deruelle C, Rondan C, Salle-Collemiche X, Bastard-Rosset D, Da Fonséca $D$ (2008): Attention to low- and high-spatial frequencies in categorizing facial identities, emotions and gender in children with autism. Brain Cogn 66:115-123.

7. Curby KM, Schyns PG, Gosselin F, Gauthier I (2003): Differential use of spatial frequency scales for face recognition in a person with Asperger's syndrome. J Vis 3:821.

8. de Jong MC, van Engeland H, Kemner C (2008): Attentional effects of gaze shifts are influenced by emotion and spatial frequency, but not in autism. J Am Acad Child Adolesc Psychiatry 47:443-454.

9. Deruelle C, Rondan C, Gepner B, Tardif C (2004): Spatial frequency and face processing in children with autism and Asperger syndrome. J Autism Dev Disord 34:199-210.

10. Goldstein EB (1999): Sensation and Perception. Pacific Grove, CA: Brooks/ Cole.

11. De Valois RL, De Valois KK (1988): Spatial Vision. New York: Oxford University Press.

12. Boeschoten MA, Kenemans JL, van Engeland H, Kemner C (2007): Abnormal spatial frequency processing in high-functioning children with pervasive developmental disorder (PDD). Clin Neurophysiol 118:20762088.

13. Bar M (2004): Visual objects in context. Nat Rev Neurosci 5:617-629.

14. Goffaux V, Rossion B (2006): Faces are "spatial"- holistic face perception is supported by low spatial frequencies. J Exp Psychol Hum Percept Perform 32:1023-1039.

15. Morrison DJ, Schyns PG (2001): Usage of spatial scales for the categorization of faces, objects, and scenes. Psychon Bull Rev 8:454-469.
16. Winston JS, Vuilleumier P, Dolan RJ (2003): Effects of low-spatial frequency components of fearful faces on fusiform cortex activity. Curr Biol 13:1824-1829.

17. Pourtois G, Dan ES, Grandjean D, Sander D, Vuilleumier P (2005): Enhanced extrastriate visual response to bandpass spatial frequency filtered fearful faces: Time course and topographic evoked-potentials mapping. Hum Brain Mapp 26:65-79.

18. Johnson MH (2005): Subcortical face processing. Nat Rev Neurosci 6:766-774.

19. Vlamings PHJM, Goffaux V, Kemner C (2009): Is the early modulation of brain activity by fearful facial expressions primarily mediated by coarse low spatial frequency information? J Vis 9:1-13.

20. Milne E, Scope A, Pascalis O, Buckley D, Makeig S (2009): Independent component analysis reveals atypical electroencephalographic activity during visual perception in individuals with autism. Biol Psychiatry 65: 22-30.

21. Elsabbagh M, Johnson MH (2007): Infancy and autism: Progress, prospects, and challenges. Prog Brain Res 164:355-383.

22. Dawson G, Webb SJ, Carver L, Panagiotides H, McPartland J (2004): Young children with autism show atypical brain responses to fearful versus neutral facial expressions of emotion. Dev Sci 7:340-359.

23. Webb SJ, Dawson G, Bernier R, Panagiotides H (2006): ERP evidence of atypical face processing in young children with autism. J Autism Dev Disord 36:881-890.

24. Walker-Andrews AS, Dickson LR (1997): Infant's understanding of affect In: Hale SH, editor. The Development of Social Cognition. Hove, UK: Psychology Press, 162-186.

25. Brecelj J (2003): From immature to mature pattern ERG and VEP. Doc Ophthalmol 107:215-224.

26. Kuefner D, de Heering A, Jacques C, Palermo-Soler E, Rossion B (2010): Early visually evoked electrophysiological responses over the human brain (P1, N170) show stable patterns of face-sensitivity from 4 years to adulthood. Front Hum Neurosci 3:67.

27. Batty M, Taylor MJ (2006): The development of emotional face processing during childhood. Dev Sci 9:207-220.

28. Henson RN, Goshen-Gottstein Y, Ganel T, Otten LJ, Quayle A, Rugg MD (2003): Electrophysiological and hemodynamic correlates of face perception, recognition and priming. Cereb Cortex 13:793-805.

29. Holmes A, Green S, Vuilleumier P (2005): The involvement of distinct visual channels in rapid attention towards fearful facial expressions. Cogn Emot 19:899-922.

30. Lord C, Rutter M, Le Couteur A (1994): Autism Diagnostic InterviewRevised: A revised version of a diagnostic interview for caregivers of individuals with possible pervasive developmental disorders. J Autism Dev Disord 24:659-685.

31. Lord C, Rutter M, Goode S, Heemsbergen J, Jordan H, Mawhood L, Schopler E (1989): Autism Diagnostic Observation Schedule: A standard observation of communicative and social behavior. J Autism Dev Disord 19:185-212.

32. Rutter M, Baily A, Lord C (2003): Social Communication Questionnaire (SCQ). Los Angeles: Western Psychological Services.

33. Vuilleumier P, Armony JL, Driver J, Dolan RJ (2003): Distinct spatial frequency sensitivities for processing faces and emotional expressions. Nat Neurosci 6:624-631.

34. Tottenham N, Borscheid A, Ellertsen K, Marcus DJ, Nelson CA (2002): Categorization of facial expressions in children and adults: Establishing a larger stimulus set. J Cogn Neurosci 14:S74.

35. Tabachnik BG, Fidell LS (2001): Using Multivariate Statistics. Boston: Allyn and Bacon.

36. Kuschner ES, Bennetto L, Yost K (2007): Patterns of nonverbal cognitive functioning in young children with autism spectrum disorders. J Autism Dev Disord 37:795-807.

37. Plant GT (1983): Transient visually evoked potentials to sinusoidal gratings in optic neuritis. J Neurol Neurosurg Psychiatry 46:1125-1133.

38. Reed JL, Marx MS, May JG (1984): Spatial frequency tuning in the visual evoked potential elicited by sine-wave gratings. Vis Res 24:1057-1062.

39. Vassilev A, Mihaylova M, Bonnet C (2002): On the delay in processing high spatial frequency visual information: Reaction time and VEP latency study of the effect of local intensity of stimulation. Vis Res 42:851864.

40. Kenemans JL, Baas JM, Mangun GR, Lijfijt M, Verbaten MN (2000): On the processing of spatial frequencies as revealed by evoked-potential source modeling. Clin Neurophysiol 111:1113-1123. 
41. Baas JM, Kenemans JL, Mangun GR (2002): Selective attention to spatial frequency: An ERP and source localization analysis. Clin Neurophysiol 113:1840-1854.

42. Gordon GE, McCulloch DL (1999): A VEP investigation of parallel visual pathway development in primary school age children. Doc Ophthalmol 99:1-10.

43. Skotun BC, Skoyles JR (2007): Some remarks on the use of visually evoked potentials to measure magnocellular activity. Clin Neurophysiol 118:1903-1905.

44. Mayer DL, Dobson V (1982): Visual acuity development in infants and young children, as assessed by operant preferential looking. Vis Res 22:1141-1151.

45. Laycock R, Crewther SG, Crewther DP (2007): A role for the "magnocellular advantage" in visual impairments in neurodevelopmental and psychiatric disorders. Neurosci Biobehav Rev 31:363-376.

46. Simmons DR, Robertson AE, McKay LS, Toal E, McAleer P, Pollick FE (2009): Vision in autism spectrum disorders. Vis Res 49:2705-2739.

47. Golorai G, Grill-Spector K, Reiss AL (2006): Autism and the development of face processing. Clin Neurosci Res 6:145-160.

48. Jones W, Carr K, Klin A (2008): Absence of preferential looking the eyes of approaching adults predicts level of social disability in 2-year-old toddlers with autism spectrum disorder. Arch Gen Psychiatry 65:946-954.

49. Klin A, Jones W, Schultz R, Volkmar F, Cohen D (2009): Visual fixation patterns during viewing of naturalistic social situations as predictors of social competence in individuals with autism. Arch Gen Psychiatry 59: 809-816.

50. Thomas KM, Drevets WC, Whalen PJ, Eccard CH, Dahl RE, Ryan ND, Casey BJ (2001): Amygdala response to facial expressions in children and adults. Biol Psychiatry 49:309-316.
51. Happé F, Ronald A, Plomin R (2006): Time to give up on a single explanation for autism. Nat Neurosci 9:1218-1220.

52. Rapin I, Tuchman F (2008): What is new in autism? Curr Opin Neurol 21:143-149.

53. de Wit TC, Schlooz WA, Hulstijn W, van Lier R (2007): Visual completion and complexity of visual shape in children with pervasive developmental disorder. Eur Child Adolesc Psychiatry 16:168-177.

54. Rinehart NJ, Bradshaw JL, Moss SA, Brereton AV, Tonge BJ (2000): Atypical interference of local detail on global processing in high-functioning autism and Asperger's disorder. J Child Psychol Psychiatry 41:769-778.

55. Ozonoff S, Strayer DL, McMahon WM, Filloux F (1994): Executive function abilities in autism and Tourette syndrome: An information processing approach. J Child Psychol Psychiatry 35:1015-1032.

56. Iarocci G, Burack JA, Shore DI, Mottron L, Enns JT (2006): Global-local visual processing in high functioning children with autism: Structural vs. implicit task biases. J Autism Dev Disord 36:117-129.

57. Plaisted K, Dobler V, Bell S, Davis G (2006): The microgenesis of global perception in autism. J Autism Dev Disord 36:107-116.

58. Plaisted K, Swettenham J, Rees L (1999): Children with autism show local precedence in a divided attention task and global precedence in a selective attention task. J Child Psychol Psychiatry 40:733-742.

59. Mottron L, Burack JA, Stauder JEA, Robaey P (1999): Perceptual processing among high-functioning persons with autism. J Child Psychol Psychiatry 40:203-211.

60. Plaisted K, O'Riordan M, Baron-Cohen S (1998): Enhanced discrimination of novel, highly similar stimuli by adults with autism during a perceptual learning task. J Child Psychol Psychiatry 39:765-775. 